\title{
Effect of Alkali Activator Type on the Local UAE Sand Treated with Alkali Activated Binders
}

\author{
Bara Jarah', Mohamed G. Arab', ${ }^{1}$, Talha Junaid ${ }^{1}$, Maher Omar ${ }^{1}$ \\ ${ }^{1}$ Civil \& Environmental Engineering Department, College of Engineering, University of Sharjah \\ 27272, Sharjah, UAE \\ U16200661@sharjah.ac.ae ;marab@sharjah.ac.ae; mjunaid@sharjah.ac.ae; momar@sharjah.ac.ae \\ ${ }^{2}$ Structural Engineering Department, Mansoura University \\ Al-Gomhoria Street, Mansoura, Egypt \\ mg_arab@mans.edu.eg
}

\begin{abstract}
Unfavorable soil conditions may affect structures and pavement performance adversely during their service life. This study is a preliminary study on the use of Alkali-activated binders (AABs) known as geopolymers to stabilize surficial loose sand deposits at ambient temperature. Several mixes of fly ash (FA) and ground-granulated blast-furnace slag (GGBFS) to stabilize local dune-sands were investigated. Two different solutions were employed as reaction activators in this investigation namely sodium silicate solution (SS) and sodium hydroxide solution (SH). A precursor/soil ratio of $10 \%$ was used throughout this study. The factors studied for the geopolymerization process were activator/solids ratio, SS/SH ratio and FA/GGBFS ratio. The tested specimens were cured at a temperature of 35 degree Celsius for 8 days. Results showed that increasing SS/SH ratio from 0 to 0.5 causes a strength increase in all studied mixes, while increasing the ratio from 0.5 to 1 causes a strength reduction except in the mix with only GGBFS and $0 \%$ of fly ash. GGBFS reacts with sodium silicate to form the aluminu-silicate gel which strengthen the geopolymer sample. A preferred mix concluded in this study has a FA/GGBFS ratio of 50:50 and a SS/SH ratio of 0.5 due to its high strength and relatively economical value.
\end{abstract}

Keywords: Soil improvement; alkali activated; dune sand; fly ash, GGBFS

\section{Introduction}

Loose sand soil deposits may adversely affect the infrastructures due to low bearing capacity and high compressibility. Ground improvement techniques can be used to improve the engineering properties of the treated soil mass such as shear strength, durability, stiffness and permeability. Several chemical and mechanical techniques have been developed over the last decades to alter or improve poor soil conditions. One of the most commonly used additives used to improve the soil mechanical properties are lime, cement or a mixture of both materials [1]. These materials are usually available in the market and have proven robustness and easy adaptability in addition to their normal cost [2].

However, several negative environmental effects have been associated with the use of lime and cement. For example, cement industry is held responsible for around $7 \%$ of artificial $\mathrm{CO}_{2}$ emissions and the production of one ton of Portland cement emits approximately one ton of $\mathrm{CO}_{2}$ into the atmosphere [2], [3] and [4].

Several researchers have showed that pozzolanic materials that are rich in silica $\left(\mathrm{SiO}_{2}\right)$ and alumina $\left(\mathrm{Al}_{2} \mathrm{O}_{3}\right)$ can be activated by an alkaline solution to form binder usually referred to as geopolymers [2]. This reaction produces both calcium silicate hydrate $(\mathrm{C}-\mathrm{S}-\mathrm{H})$ and calcium aluminum hydrate $(\mathrm{C}-\mathrm{A}-\mathrm{H})$ gels, which are the main cementing binders [2]. These binders can be used as alternative to cement in soil improvement.

This highly-performance inorganic binders are what recently known as alkali-activated binders (AABs). The geopolymerization process involve several factors include the properties of pozzolanic materials, type of the activators and curing temperature. One of the major challenges that may hinder the application of the geopolymers as soil improvement technique is the curing temperature because of high sensitivity of reactions to the heat energy. The geoplomerization process will take longer curing time at ambient or low temperature range. In order to achieve higher geopolymerization rates higher ratios of the activator may be required with higher binder content. This may affect the ease of the compaction and affect the overall performance of the treated soil. This is investigated in this study by using different type of activators with different percentages of the activator solution in the binder. 
Several raw materials have been used in the literature in the geopolymer binder. Zhang et. al. [5] conducted an experimental study to examine the feasibility of using alkali-activated metakaolin binder to treat a lean clay. Soil was treated with different levels of AABs and compared the results to cement treated samples. It was concluded that the compressive strength values of geopolymer stabilized soils are much higher than the bare control soil, and higher than $5 \%$ PC stabilized soil when alkali activated metakaolin binder concentration is higher than $11 \%$. However, a minor strength growth from 7-day curing to 28-day was noticed [5]. Also, UCS results showed that the treated soils have more ductile behavior compared to bare soil samples which is preferred behavior especially for flexible pavement applications.

Another study was conducted by Rios et. al. [6] to evaluate the feasibility of using AABs to stabilize a Colombian silty sand for unpaved roads applications. Low-calcium fly ash was used as source material, sodium silicate (SS) and sodium hydroxide ( $\mathrm{SH}$ ) as alkaline solutions with different concentrations. Preparation of the alkali solution was achieved by dissolving the SH flakes in water until the required concentration is met. The activator mixed with soil was compacted statically in mold with $142 \mathrm{~mm}$ of height and $71 \mathrm{~mm}$ of diameter. Ambient temperature cured samples were subjected to UCS test. The results showed that increasing SH concentration from 4 to 10 mol, increases the compressive strength while increasing the concentration beyond $10 \mathrm{~mol}$ has an adverse effect on the UCS of the treated soil specimens.

Singhi et. al. [7] investigated soil-geopolymer incorporating slag, fly ash and blending of slag and fly ash as source materials. It was observed that molar concentration of alkali activator, alkali-to-binder ratio and percent content of binding material altogether affect the unconfined compressive strength of stabilized soil. $\mathrm{Na} / \mathrm{Al}$ and $\mathrm{Si} / \mathrm{Al}$ ratios of the geopolymer mix ultimately govern the strength of stabilized soil. It was also observed that slag content is the most dominating factor affecting unconfined compressive strength rather than $\mathrm{Na} / \mathrm{Al}$ ratio in case blending of GGBS and fly ash.

As shown earlier, few studies have studied the use of Alkali activated binders to treat loose fine sands. In this study, the use of the alkali activated binders to treat loose fine sand is examined. The effect of the precursor type and its percentage on the unit weight and the compressive strength of the treated soil has been examined. The main objectives of the current study are summarized as following:

1. Investigate the effect of both activator content and activator type on the treated soil dry density and compressive strength.

2. Investigate the effect the source of geopolymer raw material on the treated soil dry density and compressive strength.

3. Optimization of the geopolymer components in order to achieve both high dry density in the field application with high compressive strength within 7 days of curing time.

\section{Materials and methodology}

\subsection{Sand}

Local sandy soil was collected from Sharjah beach located at $25^{\circ} 23^{\prime} 26.7^{\prime \prime}$ north and $55^{\circ} 24^{\prime} 58.7^{\prime \prime}$ east and stored in the lab under room temperature. Sieve analysis of the sandy soil is shown in Fig. 1. The grading characteristics $\mathrm{D}_{10}, \mathrm{D}_{30}$, $\mathrm{D}_{60}$ are $0.085 \mathrm{~mm}, 0.13 \mathrm{~mm}$ and $0.25 \mathrm{~mm}$ respectively, while the uniformity coefficient $\mathrm{C}_{\mathrm{u}}$ and the coefficient of gradation $\mathrm{C}_{\mathrm{c}}$ are 2.94 and 0.8 respectively. Using the Unified Soil Classification System, the soil is classified as poorly graded sand 'SP'. 


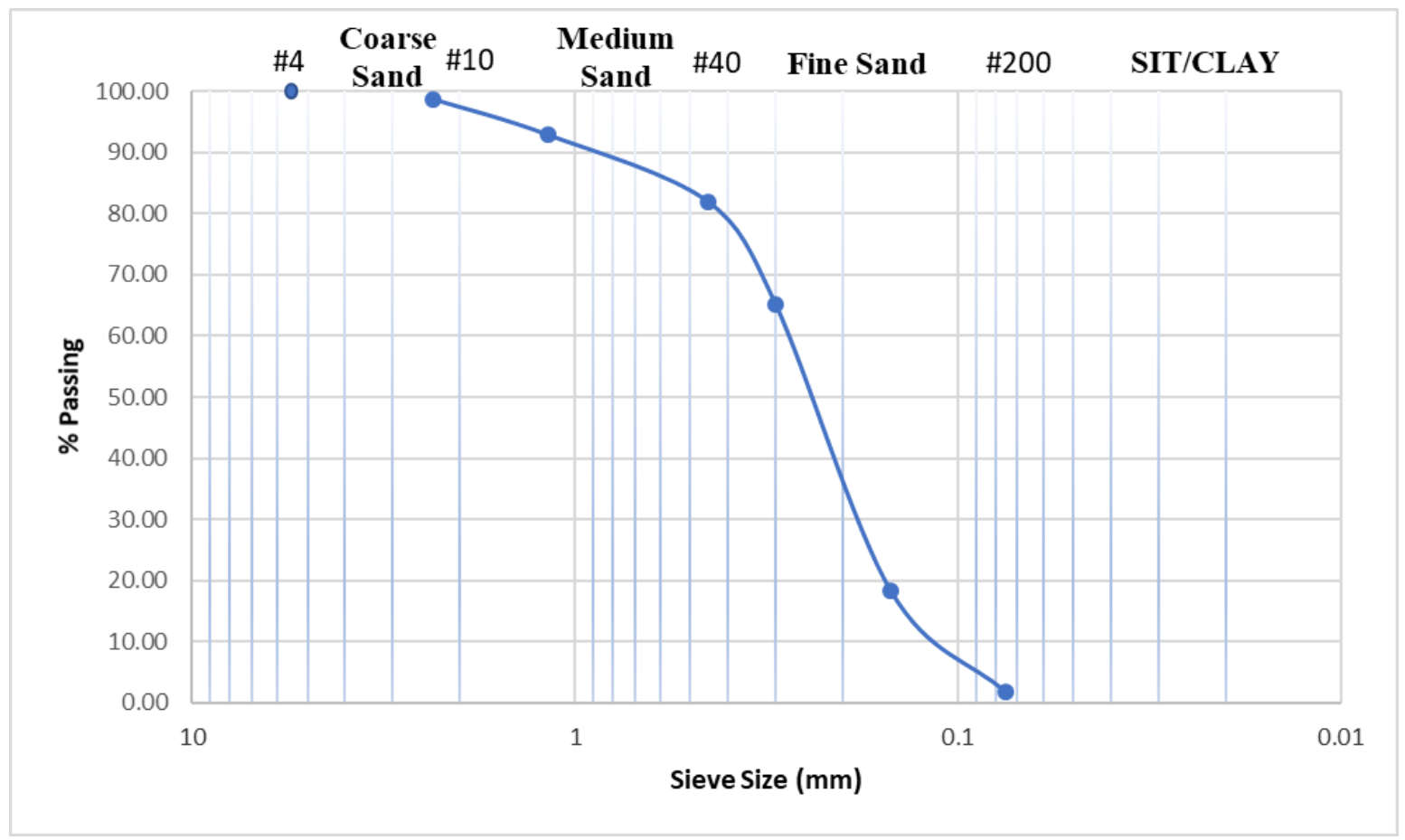

Fig. 1: GSD Curve of the treated soil

Standard proctor compaction test was conducted for the bare soil according to the ASTM-698. The compaction curve in Fig. 2 shows the maximum dry unit weight of $18.96 \mathrm{kN} / \mathrm{m}^{3}$ with an optimum moisture content of about $10 \%$.

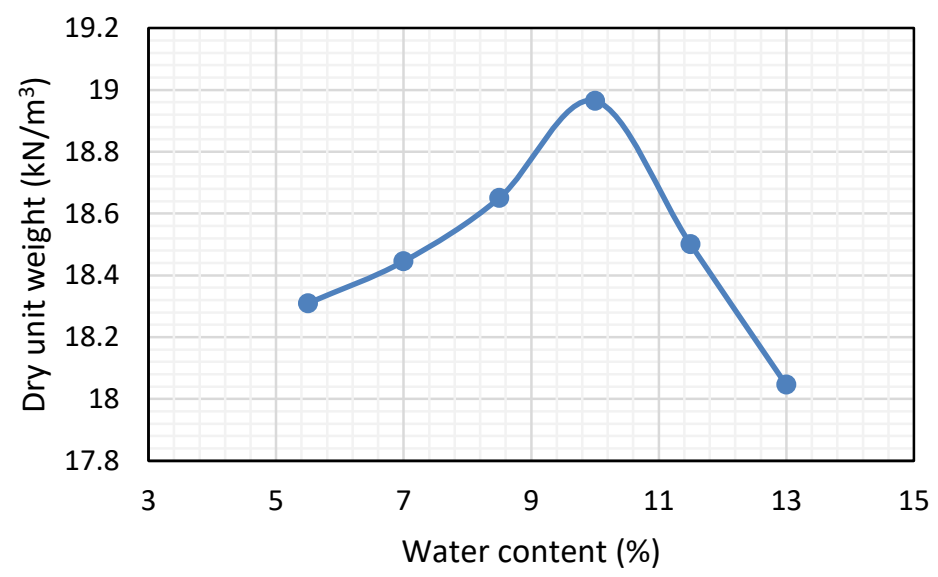

Fig. 2: Compaction curve for the soil

\subsection{AAB components}

\subsubsection{Fly ash (FA)}

A class ' $F$ ' fly ash was provided by green cement ventures company as 1.5 tons bag. According to ASTM-C618 standards, there are three types of $\mathrm{FA}$, i.e. class ' $\mathrm{F}$ ', class ' $\mathrm{C}$ ' and class ' $\mathrm{N}$ ', based on its main content of the constituent material. Due to their pozzolanic characteristics, class ' $\mathrm{F}$ ' and class ' $\mathrm{C}$ ' are commonly used as cement partial replacement material [8]. The main difference between the two classes is the calcium (Ca) content where class ' $\mathrm{F}$ ' has $\mathrm{Ca}$ less than $10 \%$, 
while it is higher than $10 \%$ in class ' $C$ '. Another difference is that class ' $F$ ' has a higher loss on ignition (LOI) than class ' $\mathrm{C}$ ', which is a direct measure of unburned carbon content in FA.

\subsubsection{Ground granulated blast furnace slag (GGBFS)}

Ground granulated blast furnace slag was provided by super cement company. It is delivered as 1.2 tons bag with white powder of slag fines.

\subsubsection{Activators}

$\mathrm{NaOH}$ solution:

Sodium hydroxide was provided from Emirates Scientific and Technical Supplies company as $50 \mathrm{~kg}$ box of $\mathrm{NaOH}$ dry white pellets. A solution of 8 molar concentration was prepared and used in the testing program applying the following procedure:

1. $262 \mathrm{~g}$ of $\mathrm{NaOH}$ pellets were weighted using an electronic balance.

2. Flakes were put in a glass container.

3. Water was added gradually to reach $1 \mathrm{~kg}$ of the solution with careful mixing.

4. The solution was left for 24 hours in order to be used properly and safely.

$\underline{\mathrm{Na}_{2}} \underline{\mathrm{SiO}}_{3}$ solution:

Sodium silicate solution $\left(\mathrm{Na}_{2} \mathrm{SiO}_{3}\right)$ with density between 1.296 and $1.396 \mathrm{~g} / \mathrm{ml}$ produced by Merck, KGaA, Germany and procured from ESTS, UAE was used. The properties of the used sodium silicate solution is shown in Table 1.

Table 1: Properties of sodium silicate solution used in the study

\begin{tabular}{|l|l|}
\hline \multicolumn{1}{|c|}{ Identity } & \multicolumn{1}{c|}{ Passes test } \\
\hline Assay (acidimetric, $\left.\mathrm{Na}_{2} \mathrm{O}\right)$ & $(7.5-8.5) \%$ \\
\hline Assay (acidimetric, $\left.\mathrm{SiO}_{2}\right)$ & $(25.5-28.5) \%$ \\
\hline Density $\left(\right.$ at $\left.20^{\circ} \mathrm{C}\right)$ & $(1.296-1.396) \mathrm{g} / \mathrm{ml}$ \\
\hline Carbonate $\left(\right.$ as $\left.\mathrm{CO}_{2}\right)$ & Passes test \\
\hline $\mathrm{Fe}$ (Iron) & $\leq 50 \mathrm{ppm}$ \\
\hline Heavy metals $($ as $\mathrm{Pb})$ & $\leq 50 \mathrm{ppm}$ \\
\hline
\end{tabular}

\subsection{Mix preparation}

The soil was prepared by sieving on \#4 sieve to exclude any large items. The minus-4 material was collected and heated using the laboratory oven at $100{ }^{\circ} \mathrm{C}$ temperature for 24 hours to get rid of any free water. The soil was totally dried to exclude water content that could adversely affect the geopolymer reactions and calculations. A sample of $5 \mathrm{~kg}$ of minus- 4 soil was prepared and $10 \%$ of this quantity was added as percentage of precursor as: FA only, FA and GGBFS as a ratio of 50:50 or GGBFS only. The soil-precursor mix was carefully hand mixed for seven minutes forming the solid part of the soil treated with geopolymer.

On the other hand, five activator/solid ratios for each mix were prepared in order to construct the compaction curve using standard energy. Moreover, two different solutions were used as alkali-activators: 8-molar $\mathrm{NaOH}$ and $\mathrm{Na}_{2} \mathrm{SiO}_{3}$. The activators- in case of using two solutions - were mixed together and added to the solid mix gradually with careful mixing. 
The precursor/soil ratio was fixed to $10 \%$. On the other hand, three combinations of different percentages of FA and GGBFS were used 100:0, 50:50 and 0:100 while the $\mathrm{Na}_{2} \mathrm{SiO}_{3} / \mathrm{NaOH}(\mathrm{SS} / \mathrm{SH})$ ratios were $0,0.5$ and 1. Five levels of activator content were tested to construct the compaction curve and to find the optimum activator content with the corresponding dry unit weight for each mix. The table below shows the mixes prepared with their identification.

Table 2: Details of the binder mixes used and their designations

\begin{tabular}{||c|l|c|c|c||}
\hline \multirow{2}{*}{ No. } & \multirow{2}{*}{ ID } & \multicolumn{2}{|c||}{ precursor (solids) } & $\begin{array}{c}\text { Alkali- } \\
\text { Activators } \\
\text { (liquids) }\end{array}$ \\
\cline { 3 - 5 } & & $\begin{array}{c}\text { FA } \\
\text { (\%) }\end{array}$ & GGBFS (\%) & SS/SH \\
\hline \hline $\mathbf{1}$ & F100-G0-S0 & 100 & 0 & 0 \\
\hline $\mathbf{2}$ & F100-G0-S0.5 & 100 & 0 & 0.5 \\
\hline $\mathbf{3}$ & F100-G0-S1 & 100 & 0 & 1 \\
\hline \hline $\mathbf{4}$ & F50-G50-S0 & 50 & 50 & 0 \\
\hline $\mathbf{5}$ & F50-G50-S0.5 & 50 & 50 & 0.5 \\
\hline $\mathbf{6}$ & F50-G50-S1 & 50 & 0 & 1 \\
\hline \hline $\mathbf{7}$ & F0-G100-S0 & 0 & 100 & 0 \\
\hline $\mathbf{8}$ & F0-G100-S0.5 & 0 & 100 & 0.5 \\
\hline $\mathbf{9}$ & F0-G100-S1 & 0 & 100 & 1 \\
\hline \hline
\end{tabular}

\subsection{Compaction}

Samples were prepared by compacting the prepared mixes following ASTM-D698 standards. The mixes were casted in 4-inch standard proctor molds with 3 layers and 25 hammer blows for each layer resulting in $593 \mathrm{kN} . \mathrm{m} / \mathrm{m}^{3}$ effort. The standard hammer weighing $24.5 \mathrm{~N}$ was lifted and dropped through a vertical distance of $308 \mathrm{~mm}$. The hammer hits were distributed around the soil mix to make sure all geopolymer mix particles were compacted evenly. Any excess material is trimmed using a groove to level the sample correctly. Two replicates from each mix were prepared to minimize personal and instrumental error. After that, the filled molds were put in the oven at $35{ }^{\circ} \mathrm{C}$ temperature for 24 hours to cure and harden so that it can be extracted later using the extrusion oil jack.

\subsection{Curing}

Once they were extruded, samples were cured in the humidity chamber at an ambient temperature of $\left(33 \pm 2{ }^{\circ} \mathrm{C}\right)$ for 8 days before testing their strength. This temperature was set to simulate the real weather of the UAE since the average temperature during the year is from 30 to $35^{\circ} \mathrm{C}$. Since usual curing time in cement and concrete starts with 7 days, the same period was set to test geopolymer samples. However, the first day of hardening was added to the curing time resulting in total 8 days period of curing.

\subsection{UCS test}

After curing, samples were totally dried and then were taken to the UCS machine to determine their strength. The digital Vernier caliper was used to precisely measure the diameter of each sample four times in different locations and then the average of these readings was recorded. This would minimize the possible uncertainty caused by instrumental and personal error. This diameter was used to calculate the real base area of the sample to precisely calculate the maximum stress by dividing the maximum force applied by the base area. Each sample was carefully centered on the machine base plate in order 
to exclude any eccentric loadings. The base plate had lifted up the sample towards the top plate and once they got in touch, the force reading started to appear on screen. The rate of loading was set to be $0.050 \mathrm{kN} / \mathrm{sec}$.

\section{Results}

\subsection{Compaction}

\subsection{1 (F100-G0) precursor ratio}

Fig. 3 shows the compaction curves of the first three mixes containing only fly ash as a precursor with no GGBFS. Three different levels of the ratio of SS/SH are studied: 0, 0.5 and 1 forming the mixes: F100-G0-S0-H8, F100-G0-S0.5H8 and F100-G0-S1-H8 respectively.

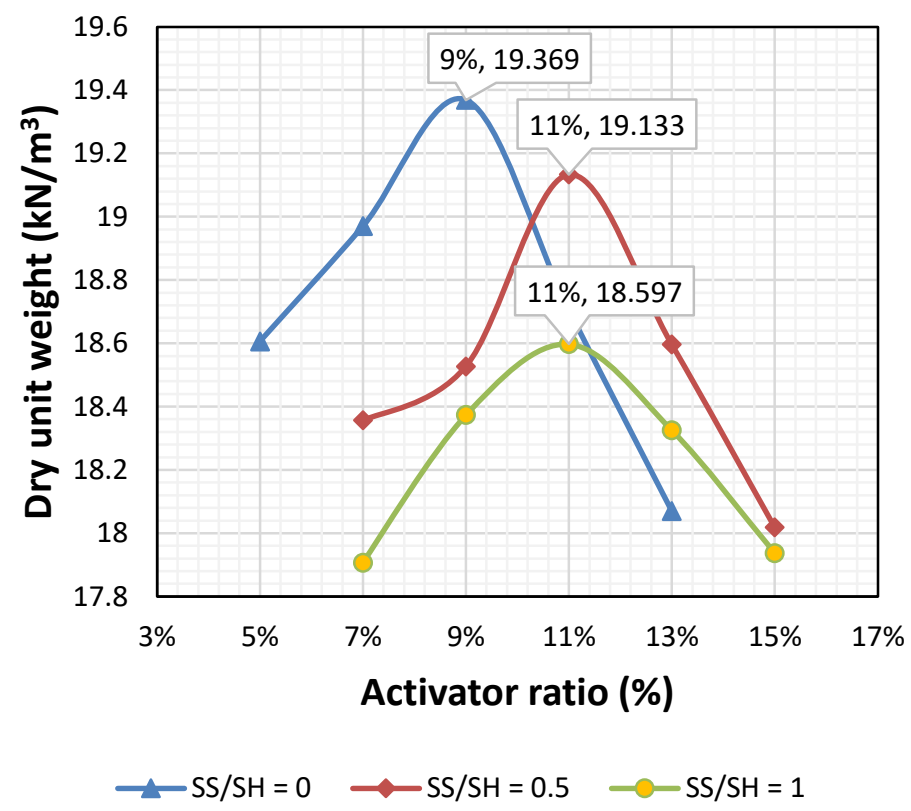

Fig. 3: Compaction curves of F100-G0 mixes

The first mix contains SH solution only as activator, while the second and the third contain SS and SH with the ratios 0.5 and 1 respectively. The maximum dry unit weight for mix 1 (F100-G0-S0-H8) is $19.37 \mathrm{kN} / \mathrm{m}^{3}$ with optimum precursor content of $9 \%$. However, adding SS to the fly ash causes the optimum precursor content to increase to $11 \%$ and the dry unit weight to decrease down to $18.59 \mathrm{kN} / \mathrm{m}^{3}$.

\subsection{2 (F50-G50) precursor ratio}

In these mixes, a mix of FA and GGBFS precursors was used with a ratio of 50:50. The maximum dry unit weight and activator content were not significantly affected by changing the SS/SH ratio as shown in Fig. 4. However, these mixes have exhibited the highest values of dry unit weight compared to other mixes. This could be contributed to the difference in grain size for both precursors causing void reduction and better grain distribution and density of the mix. 

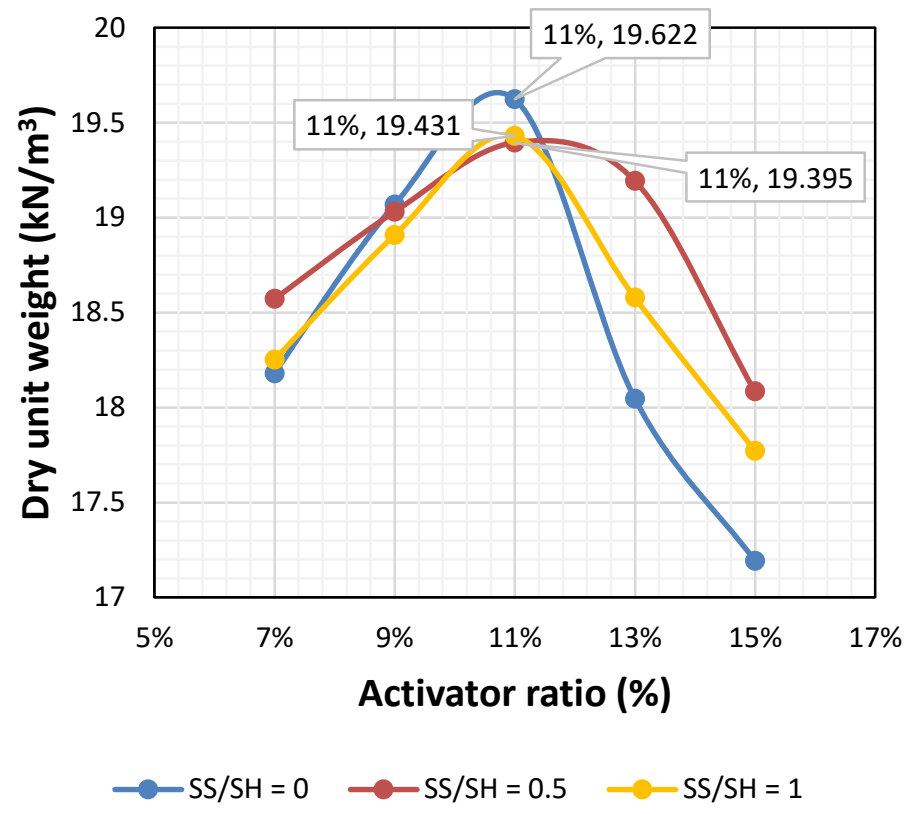

Fig. 4: Compaction curves of F50-G50 mixes

\subsection{3 (F0-G100) precursor ratio}

The last three studied mixes don't contain fly ash, and instead depend only on GGBFS as a precursor. As shown in Fig. 5, the dry unit weight for the three mixes (F0-G100-S0-H8, F0-G100-S0.5-H8 and F0-G100-S1-H8) are 18.69, 18.89 and $19.01 \mathrm{kN} / \mathrm{m}^{3}$ respectively and optimum activator contents are $11 \%, 13 \%$ and $13 \%$. Increasing the percentage of sodium silicate activator increases clearly the dry unit weight. This may be contributed to the effective reaction between GGBFS and SS activator forming a strong and dense binding gel.

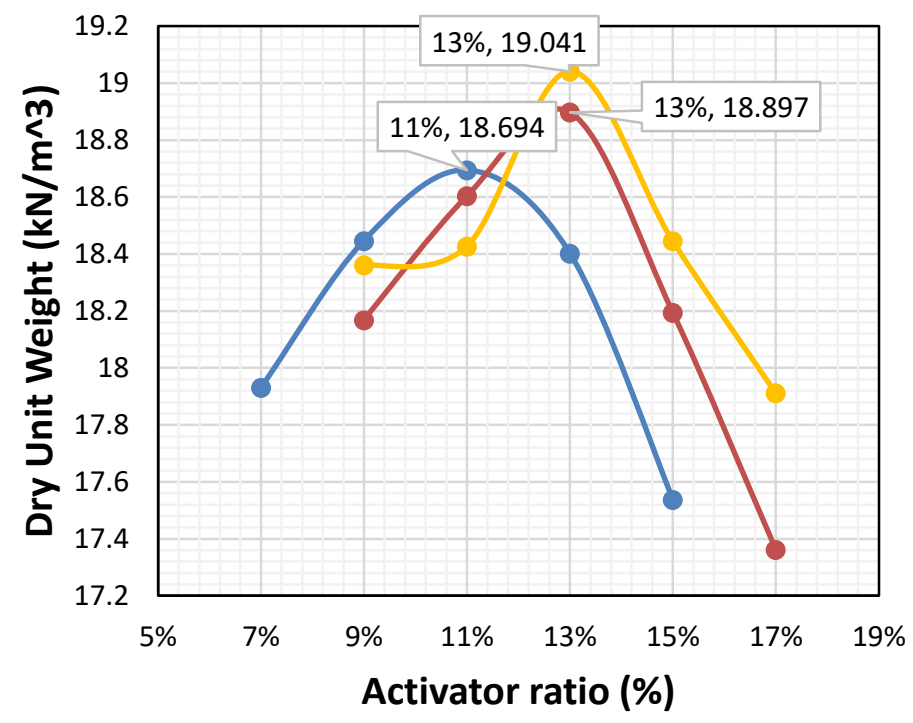

$\longrightarrow \mathrm{SS} / \mathrm{SH}=0 \longrightarrow \mathrm{SS} / \mathrm{SH}=0.5 \longrightarrow \mathrm{SS} / \mathrm{SH}=1$

Fig. 5: Compaction curves of F0-G100 mixes 
Fig. 6 shows the effect of the sodium silicate ratio on the dry unit weight of the geopolymer mix. Generally, the dry weight decreases in the mixes containing fly ash when increasing the ratio SS/SH. In mix F50-G50, the unit weight stays constant while increasing the ratio from 0.5 to 1 . On the other hand, the unit weight of the mixes containing GGBFS only as binder increases when increasing the $\mathrm{SS} / \mathrm{SH}$ ratio from 0.5 to 1 , while it is almost constant when changing from 0.5 .

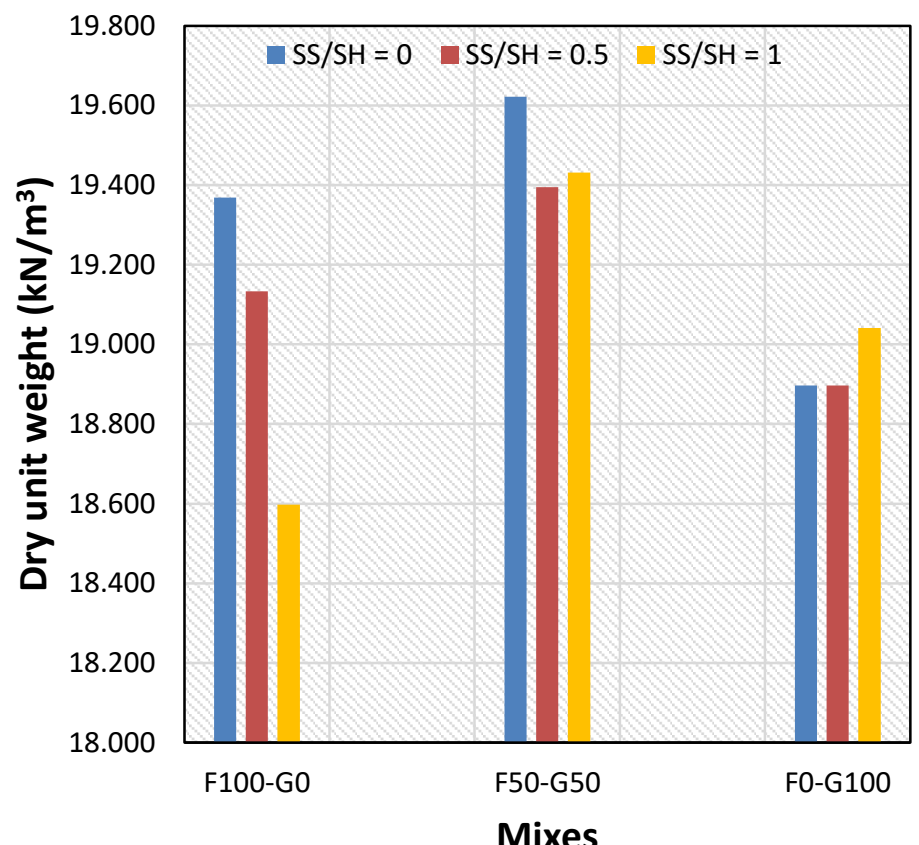

\subsection{UCS}

Fig. 6: The effect of sodium silicate ratio on dry unit weight

Summary of the UCS peak strength for average of the two replicates treated with different AAB mixes is shown in Fig. 6. It can be noted from the table the increase of UCS peak strength with the increase in SS content. A higher density of a sample means more compressed particles and less voids which logically results in a higher capacity to carry loads. Generally, every increase in GGBFS ratio causes an increase in strength which contributes to its higher density compared to FA. Moreover, Increasing the ratio of SS causes a dramatic increase in the compressive strength due to the geopolymerization reaction resulting in aluminu-silicate gel. In mixes F100-G0, the maximum strength is when using $\mathrm{SS} / \mathrm{SH}$ of 0.5 and it will decrease when this ratio increase. Although 5.44 and $6.75 \mathrm{MPa}$ are considered relatively large strength values for non-reinforced soil samples, they are on the other hand the lowest strength values of all tested mixes. This indicates a weak reaction between fly ash and sodium hydroxide or silicate which emphasis the fact that fly ash works as filling material rather than a strong precursor. Similarly, mixes of F50-G50 follow the same behavior as response to the of SS/SH ratio change, but with less strength reduction. This is due to the increase of GGBFS which reacts perfectly with SS to form a strong binding gel. What emphasis this is the one-direction strength increase when using GGBFS alone instead of using a blending with FA. Even though SS is very effective, it is on the other hand very expensive compared to other components of the geopolymers, so its percentage needs to be reduced in order to have an economical mix. Figure 7 below shows the effect of sodium silicate ratio on strength of the tested mixes. 


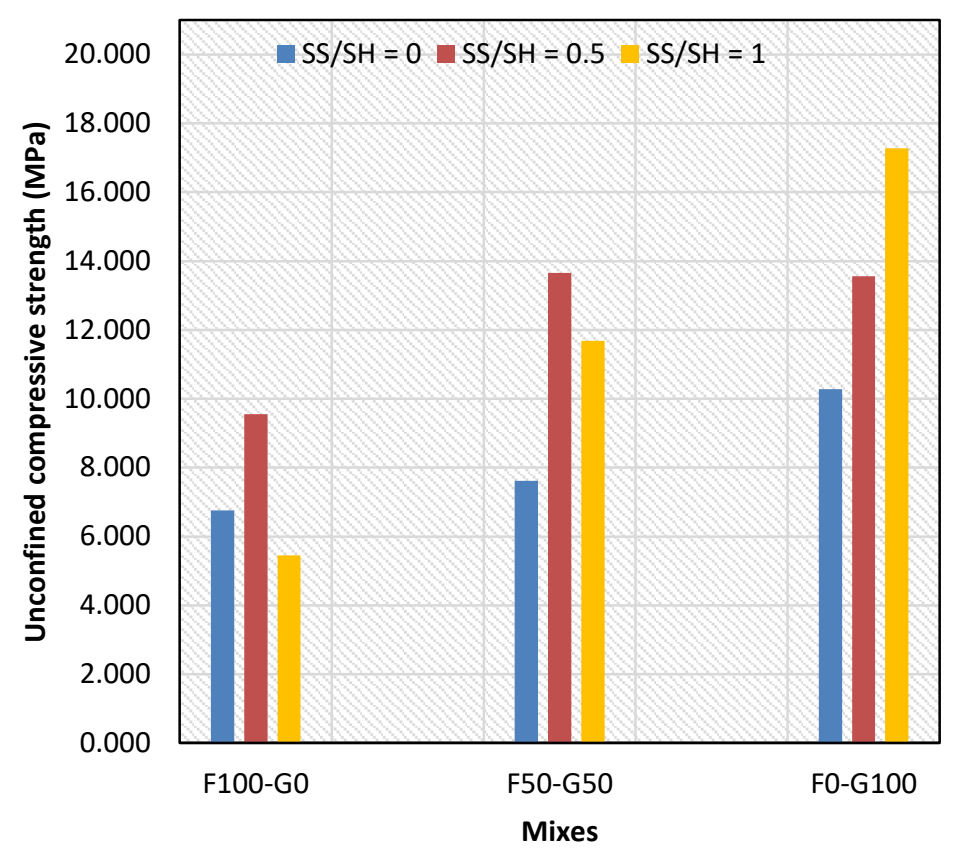

Fig. 7: The effect of sodium silicate ratio on strength

\subsection{Accuracy}

There are some sources of error that should be taken in consideration during preparation and testing procedure. Preparation of $\mathrm{NaOH}$ solution could have an error as some pellets may did not dissolve perfectly affecting the real concentration. In mixes with high activator contents, the compaction operation is hard and has some errors in dry unit weight value since the liquid mix could go out the mold. Some parts of liquid mixes could be sticked to the hammer base and could affect the compacted mix. The uncertainties of weighing balance, Vernier caliper and the UCS machine were $\pm 0.001 \mathrm{~g}, \pm$ $0.01 \mathrm{~cm}$ and $\pm 0.1 \mathrm{kN}$ respectively which doesn't affect the results significantly. Another source of error could be the personal error when calculating the molds volumes and dry unit weights.

\subsection{Limitations}

Typically, analytical studies have limitations due to assumptions, data lack, regional limitations and other reasons. Regionally, this study is limited to Sharjah emirate's soil, and could be not valid to other regions. Using other types of soil may result in different results than obtained in this study due to variability in chemical contents and particles gradation. Another limitation is the lack of data as these types of studies are still recent.

\section{Conclusion}

Experimental investigation was carried out on local sandy soil-geopolymer incorporating FA, GGBFS and their blending as source materials. The following points were concluded from the study:

1. The compressive strength of soil is directly proportional to the dry unit weight

2. Increasing SS/SH ratio from 0 to 0.5 causes a strength increase in all studied mixes, while increasing the ratio from 0.5 to 1 causes a strength decrease except in the case of mix F0-G100, the strength continues increasing with SS/SH ratio increasing.

3. GGBFS contains aluminum that reacts with sodium silicate to form the aluminu-silicate gel which strengthen the geopolymer sample.

4. The minimum and maximum strengths were achieved with mixes F100-G0-S0 and F0-G100-S1 respectively 
5. The best proposed mix is F50-G50-S0.5-H8 due to its high strength and relatively economical value.

\section{Acknowledgements}

The work described herein was supported by University of Sharjah (UoS) under grant number 18020401102. The are grateful for this support. Any opinions or positions expressed in this article are the authors only, and do not reflect opinions or positions of the UOS.

\section{References}

[1] M. De Malaxage, P. Employant, and C. Agent, "i 1 r e a," pp. 721-724, 1979.

[2] S. Pourakbar, B. K. Huat, S. Pourakbar, and B. K. Huat, "A review of alternatives traditional cementitious binders for engineering improvement of soils A review of alternatives traditional cementitious binders for engineering improvement of soils," Int. J. Geotech. Eng., vol. 6362, no. December, pp. 1-11, 2017.

[3] J. Davidovits, "Properties of Geopolymer Cements," First Int. Conf. Alkaline Cem. Concr., pp. 131-149, 1994.

[4] R. McCaffrey, "Climate change and the cement industry," GCL Mag., no. October, p. 5, 2002.

[5] M. Zhang, H. Guo, T. El-korchi, G. Zhang, and M. Tao, "Experimental feasibility study of geopolymer as the nextgeneration soil stabilizer," vol. 47, pp. 1468-1478, 2013.

[6] S. Rios, C. Ramos, A. Viana, N. Cruz, and C. Rodrigues, "Colombian Soil Stabilized with Geopolymers for Low Cost Roads," vol. 143, no. Ictg, pp. 1392-1400, 2016.

[7] B. Singhi, A. Islam, and L. M. Ali, "Investigation on Soil - Geopolymer with Slag, Fly Ash and Their Blending," pp. 393-400, 2016.

[8] A. Wardhono, "Comparison Study of Class F and Class C Fly Ashes as Cement Replacement Material on Strength Development of Non-Cement Mortar," IOP Conf. Ser. Mater. Sci. Eng., vol. 288, no. 1, pp. 0-6, 2018. 